\title{
Refined sugar intake in Australian children
}

\author{
Shawn M Somerset* \\ Nutrition Unit, School of Health Science, Griffith University, PMB 50, Gold Coast, Queensland 9726, Australia
}

Submitted 21 December 2001: Accepted 9 June 2003

\begin{abstract}
Objective: To estimate the intake of refined sugar in Australian children and adolescents, aged $2-18$ years.

Design: Foods contributing to total sugar intake were identified using data from the National Nutrition Survey 1995 (NNS95), the most recent national dietary survey of the Australian population. The top 100 foods represented means of 85\% (range 79-91\%) and $82 \%$ (range $78-85 \%$ ) of total sugar intake for boys and girls, respectively. Using published Australian food composition data (NUTTAB95), the proportion of total sugar being refined sugar was estimated for each food. Where published food composition data were not available, calculations from ingredients and manufacturer's information were used.

Subjects: The NNS95 assessed the dietary intake of a random sample of the Australian population, aged $2-18$ years $(n=3007)$.

Results: Mean daily intakes of refined sugar ranged from 26.9 to $78.3 \mathrm{~g}$ for 2-18-yearold girls, representing $6.6-14.8 \%$ of total energy intake. Corresponding figures for boys were 27.0 to $81.6 \mathrm{~g}$ and $8.0-14.0 \%$, respectively. Of the 10 highest sources of refined sugar for each age group, sweetened beverages, especially cola-type beverages, were the most prominent.

Conclusion: Refined sugar is an important contributor to dietary energy in Australian children. Sweetened beverages such as soft drinks and cordials were substantial sources of refined sugar and represent a potential target for campaigns to reduce refined sugar intake. Better access to information on the amounts of sugar added to processed food is essential for appropriate monitoring of this important energy source.
\end{abstract}

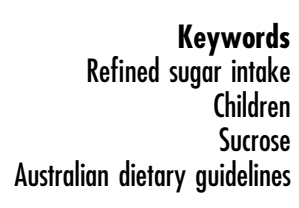

Obesity is a major global health issue ${ }^{1}$. The most recent Australian national nutrition survey indicates that at least $20 \%$ of children in Australia are overweight or obese ${ }^{2}$. Diets high in added sugar have been linked to increased frequency of obesity in children ${ }^{3}$.

Australian Dietary Guidelines for both adults and children recommend that Australians consume 'moderate amounts of sugar or foods containing added sugar' ${ }^{4,5}$. Despite the prominence of sugar in the dietary guidelines, there is very little information on how much refined sugar Australians - particularly children - consume. In estimating the intake of refined sugar, terminology is important, because it conveys the intention of such estimates. Baghurst et al. ${ }^{6}$ referred to two dietary items: 'discretionary sugars', defined as 'all refined sugars that are added to beverages or breakfast cereals at the table' (almost exclusively sucrose); and 'added refined sugars', defined as 'sugars added to food and drinks either in commercial or domestic food preparation'. This latter definition includes sucrose, lactose, glucose, maltose and fructose. A third term, 'free sugars', noted in a recent report by the World Health Organization (WHO) ${ }^{1}$, refers to 'all monosaccharides and disaccharides added to foods by the manufacturer, cook or consumer, plus sugars naturally present in honey, syrups and fruit juices'. Conceptually, the present study estimated refined sugar (RS), which is a combination of the terms 'discretionary sugars' and 'added refined sugars' during manufacture.

In 1989, Baghurst et al. ${ }^{6}$ published a summary of sugar intakes for Australians derived from three studies, only one of which (the Adelaide Family Study) produced data on the dietary intake of children (10-year-olds) from a sample of 315 families. This single published study on added sugar intake in Australians found that RS contributed $9 \%$ and $10 \%$ of total energy for 10-year-old girls and boys, respectively. The findings from Baghurst et al.'s study provide some reference of sugar consumption, although generalisability to the Australian population is limited.

Australian national apparent consumption data ${ }^{7}$ indicate that the per capita consumption of non-alcoholic beverages (aerated, carbonated and mineral waters) rose from 97.11 in $1992 / 3$ to 111.71 in 1995/6. Although sweetened beverages such as soft drinks comprise a 
substantial part of this category, no separate details were given on the contribution of soft drinks.

Studies in the $\mathrm{USA}^{8}$ and the $\mathrm{UK}^{9}$ have commented on sugar intakes in children, but experienced the common problem of being unable to differentiate RS intake from total sugar intake. Nicklas et al. ${ }^{8}$ reported that total sucrose intake decreased but total fructose intake increased in American children from 1973 to 1988. Unlike in the USA, high-fructose corn syrup is not used as extensively as a food ingredient in Australia. Another recent US study ${ }^{10}$ estimated intakes of 14.0, 15.8, 16.1 and $16.8 \%$ of energy as added sugar for children aged 2, 3, 4 and 5 years, respectively. Clearly, RS represents an important energy source in this case, and is understandably of concern in the context of combating childhood obesity. Lien et al. ${ }^{11}$ assessed added sugar intake by quantifying servings of sugary foods, and reported an increase in servings of sugary foods and a concomitant decrease in fruits and vegetables between the ages of 14 and 21 years. However, no reference was made to the percentage of energy contributed by RS.

The National Nutrition Survey 1995 (NNS95) $^{12}$ is the most recently published survey of the national Australian diet. As such, it presents an opportunity to study the dietary sugar intake of a representative sample of the Australian population. Therefore, RS consumption by Australian children and adolescents, aged $2-18$ years, was estimated using this data source.

\section{Methods}

The present study used a methodology similar to that of Baghurst et al. ${ }^{6}$. Dietary data were derived from the $\mathrm{NNS}^{13} 5^{13}$. Foods contributing to total sugar intake were identified from NNS data. The NNS is a nationally representative sub-sample (1535 boys and 1472 girls aged 2-18 years) of the National Health Survey. It is based on a 24-hour recall of food and beverage intake, so that the data indicate food intake during the day prior to interview. The overall survey response rate was $67 \%{ }^{14}$. The top 100 contributors to total sugar intake for each age from 2 to 18 years were reviewed, as these foods supplied a substantial proportion of total sugar.

Using published food composition data, estimates of the proportion of total sugar attributable to RS in each food were calculated. Where specific published food composition data were not available, calculations from ingredients and manufacturer's information were used. General food composition data were derived from the NUTTAB95 Australian food composition database ${ }^{15}$, using the dietary analysis software FOODWORKS (Xyris Software, Brisbane, Australia). Specific information on the sucrose content of foods was derived from various sources, including two supplements to NUTTAB ${ }^{15}$, data from the US Department of Agriculture ${ }^{16}$, Australian food composition studies by Wills ${ }^{17}$ and fundamental food composition studies by Winton and Winton ${ }^{18}$. Calculations of sugar contents from ingredients and manufacturer's information were used when published data were not available, using popular and widely available recipe books ${ }^{19,20}$.

\section{Results}

The proportion of total sugar represented by added sugar was estimated in a total of about 450 separate food items. The top 100 foods represented means of $85 \%$ (range $79-91 \%$ ) and $82 \%$ (range $78-85 \%$ ) of total sugar intake for boys and girls, respectively, for each of the age groups up to 18 years (see Table 1). Average daily intakes of RS ranged from 27 to $81.6 \mathrm{~g}$ for boys and from 27 to $78.3 \mathrm{~g}$ for girls 2-18 years of age, corresponding to $432-1305 \mathrm{~kJ} \mathrm{day}^{-1}$ for boys and $430-1252 \mathrm{~kJ} \mathrm{day}^{-1}$ for girls. This represents $9-14 \%$ and $7-15 \%$ of total energy intake, respectively. Total energy intake was derived directly from NNS95 data. To provide a dietary context to the above figures, the contributions to RS intake made by the 10 highest sources for each age group are presented in Table 2.

\section{Discussion}

Estimates of RS intake in this study were made using the top 100 sources of total sugar. These foods provided means of $85 \%$ and $82 \%$ of total sugar intake in boys and girls, respectively, for the age groups up to 18 years (see Table 1). Therefore, the RS intake calculations in Table 1 are an underestimate of true consumption. The magnitude of this underestimate is not known.

Various recommendations for limits on percentage of energy as RS, which are most commonly set at around 10\% of energy, are intended for adult populations ${ }^{11,21}$. Some of the intakes reported in Table 1 exceed this recommendation. The NNS95 reported a substantial increase in energy intakes for children (15\% for boys, $11 \%$ for girls) since the previous national survey of 1985 . Clearly, added sugar is an important contributor to this energy intake, and therefore to the increase in childhood overweight and obesity in Australia. The intake of RS found in the present study is far in excess of the recently established WHO limit of $10 \%$ of energy as 'free sugar', since 'free sugar' comprises RS plus sugars naturally present in honey, syrups and fruit juices ${ }^{1}$.

The itemised account of the contributions of the 10 highest sources of dietary RS for each age group in Table 2 was done to provide a contextual insight into the meaning of percentage energy as RS. This approach has been useful for studies on dietary fat intake ${ }^{22}$. High-sugar foods are prominent right across the age groups, and the percentage RS contributed to energy generally increased with age. Kranz and Siega-Riz ${ }^{10}$ found a similar trend over the ages 2 to 5 years in a cross-sectional study in the USA. The present study was cross-sectional, and thus provides no 
indication of future RS intakes. However, in a longitudinal study, Lien et $a l^{11}$ found that intakes of sugary foods increase over the ages 14 to 21 years.

High intakes of added sugar intake might have adverse consequences. Lien et al. ${ }^{11}$ found that increased intakes of sugary foods are associated with a decreased intake of vegetables and fruits. Various studies indicate that dietary patterns in childhood are likely to have long-term consequences on diets later in life $e^{23,24}$. There is conjecture as to whether such dietary consequences translate into health or disease outcomes ${ }^{25,26}$. However, the recent WHO report on Diet, Nutrition and the Prevention of Chronic Diseases ${ }^{1}$ states clearly that closer scrutiny needs to be applied to RS intake.

Baghurst et $a l .{ }^{6}$ determined refined sugar intakes using a combination of data sources. First, dietary data were collected using self-completed, quantified food-frequency questionnaires in subsections of the Australian population in one city only, rather than the representative sample of the Australian population covered by the NNS95. Nutrient data used were a combination of British and Australian food composition data. Where direct food composition data were not available, they used analyses of ingredients combined with information from food manufacturers. However, beyond this description, no specific details of compositional calculations were noted. Thus, although a similar approach to estimating sugar intake was used in the present paper, fundamental differences in dietary data collection methods and food composition databases make direct comparison of results difficult. Similarly, comparisons of estimates of RS intake from other countries need to be considered in the context of differences in dietary intake methodology, food manufacturing practices and the structure of national food composition databases.

The present study looks at a best estimate for RS (discretionary and hidden) in the diets of children aged 2-18 years. For most manufactured foods in Australia, sucrose is the dominant sugar added ${ }^{17}$. 'Fruit juices' is the major food category where fructose and glucose are added in preference to sucrose ${ }^{17}$. In all cases, it was the amount of added sugar that was estimated. Even if, in some cases, the added sugar was fructose or glucose, these sugars were added to a concentration above that which would be expected in an unsweetened product. Of particular note is the presence of glucose and fructose in carbonated soft drinks, as documented by Wills ${ }^{17}$. In this case all three saccharides were treated as RS, since the glucose and fructose present are likely to be derived from the breakdown of added sucrose during processing.

Information on RS in Australian foods is sparse. The data for sucrose contents of Australian foods from the two NUTTAB supplements ${ }^{15}$ cover far fewer foods than those analysed in the National Nutrition Survey. Also, sucrose levels described in the NUTTAB supplements refer to total sucrose present, rather than the amount of sucrose added (above that occurring naturally) during processing. 
Table 2 Contributions to refined sugar intake $\left(\mathrm{g} \mathrm{day}^{-1}\right)$ made by the 10 highest sources for each age group

\begin{tabular}{|c|c|c|c|c|c|c|c|c|c|c|c|c|c|c|c|c|c|}
\hline & \multicolumn{17}{|c|}{ Age (years) } \\
\hline & 2 & 3 & 4 & 5 & 6 & 7 & 8 & 9 & 10 & 11 & 12 & 13 & 14 & 15 & 16 & 17 & 18 \\
\hline \multicolumn{18}{|l|}{ Boys } \\
\hline Cordial & 5.64 & 4.74 & 1.64 & 6.11 & 3.37 & 1.91 & 1.03 & 2.43 & 2.93 & 1.67 & 2.79 & 4.12 & 4.84 & 8.41 & 3.53 & 2.08 & 5.7 \\
\hline Soft drinks, non-cola & 1.69 & 3.42 & 1.78 & 3.46 & 2.39 & 5.36 & 4.09 & 3.63 & 3.38 & 1.27 & 3.99 & 6.34 & 2.34 & 6.84 & 8.32 & 6.99 & 8.77 \\
\hline Ice cream & 1.51 & & & 1.6 & 2.13 & 2.68 & 1.12 & 3 & 2.31 & 1.98 & 1.75 & 5.83 & & 3.68 & 5.26 & 5.61 & \\
\hline Chocolate & 2.67 & & 1.14 & & 2 & & & & 1.59 & & 1.99 & & & 2.46 & 2.37 & 4.73 & \\
\hline $\begin{array}{l}\text { Puffed breakfast } \\
\text { cereal, cocoa }\end{array}$ & 1.22 & & 1.58 & 1.46 & & 1.22 & & 3.19 & 2.71 & 2.68 & 3.45 & 3.37 & 2.53 & 2.61 & 5.41 & 2 & 2.3 \\
\hline Jelly & 1.01 & 1.22 & & 1.83 & & & & & & 2.24 & & & & & & & \\
\hline $\begin{array}{l}\text { Discretionary sugar } \\
\text { Jam }\end{array}$ & & $\begin{array}{l}1.05 \\
0.72\end{array}$ & 1.22 & 1.33 & 1.52 & 2.55 & 3.01 & 1.32 & 2.24 & 2.33 & 3.39 & 3.91 & 3.09 & 3.6 & 3.94 & 6.92 & 7.3 \\
\hline Confectionery & & 0.73 & & & & & & 1.86 & 5.46 & & 1.75 & 1.24 & 3.67 & 2.04 & 2.01 & 1.61 & 3.68 \\
\hline Soft drinks, cola & & & 2.08 & 2.94 & 2.37 & 1.91 & 4.36 & 3.83 & 5.96 & 3.17 & 6.03 & 7.47 & 8.64 & 13.09 & 8.37 & 18.87 & 17.52 \\
\hline Hazelnut spread & & & 1.44 & & & & & & & 1.22 & & & & & & & \\
\hline Cake/pastry & & & 2.29 & & & 1.41 & 1.24 & 3.29 & & 1.3 & & 1.29 & 1.35 & & & & \\
\hline Dairy dessert & & & 0.92 & & 0.93 & & & & & & & & & & & 1.47 & \\
\hline Iced confection & & & & 2.17 & 0.97 & 1.25 & 4 & & & & 1.4 & 2.21 & & & 1.94 & & \\
\hline Fruit juice/drink & & & & & & & 0.95 & & & 1.02 & & 1.3 & & & & & 2.27 \\
\hline $\begin{array}{l}\text { Breakfast cereal, } \\
\text { oats/high-sugar }\end{array}$ & & & & & & & & & 1.38 & & & & & & & & \\
\hline $\begin{array}{l}\text { Flavoured milk/milk } \\
\text { flavouring }\end{array}$ & & & & & & & & & & & & & 1.56 & & & & \\
\hline $\begin{array}{l}\text { Breakfast cereal, } \\
\text { mixed/high-sugar }\end{array}$ & & & & & & & & & & & & & 1.39 & & & & \\
\hline \multicolumn{18}{|l|}{ Girls } \\
\hline Cordial & 1.08 & 2.33 & 2.76 & 4.28 & 0.98 & 2.68 & 1.12 & 1.38 & 2.14 & & & 2.74 & & 3.9 & 1.88 & & 2.07 \\
\hline Soft drinks, non-cola & 0.92 & & & & 2.33 & & 3.7 & 4.65 & 1.5 & 3.83 & 1.89 & 4.21 & & 6.66 & 3.27 & 10.63 & 5.7 \\
\hline Ice cream & & & 1.62 & 2.18 & 1.07 & & & 1.26 & 2.41 & 1.67 & 2.49 & & & & & & \\
\hline Chocolate & 1.32 & 0.84 & 1.01 & & 0.98 & & 2.58 & & & 1.23 & 3.77 & & & & 5.58 & & \\
\hline $\begin{array}{l}\text { Puffed breakfast } \\
\text { cereal, cocoa }\end{array}$ & 1.23 & 1.17 & & 2.82 & & 1.18 & & & 2.13 & & 1.69 & & & & & & \\
\hline Jelly & & & & & 0.94 & & & & & & & & & 2.6 & & & \\
\hline $\begin{array}{l}\text { Discretionary sugar } \\
\text { Jam }\end{array}$ & & & 5.86 & 1.54 & 0.98 & 1.43 & & 3.16 & & 2.93 & $\begin{array}{l}1.22 \\
1.33\end{array}$ & 2.14 & & 11.38 & 3.6 & $\begin{array}{r}12.89 \\
1.36\end{array}$ & 7.3 \\
\hline Confectionery & 1.05 & & 2.35 & 3.1 & 3.16 & 2.72 & 4.6 & 3.94 & 2.45 & 2.92 & 1.3 & 8.96 & & 2.19 & 2.73 & & 1.21 \\
\hline $\begin{array}{l}\text { Soft drinks, cola } \\
\text { Hazelnut spread }\end{array}$ & & 1.17 & 4.48 & 1.57 & & 2.71 & 4.36 & 3.83 & 4.17 & 3.17 & 6.03 & 7.47 & & 13.09 & 8.37 & 18.87 & 17.52 \\
\hline Cake/pastry & 4.3 & 3.01 & 4.40 & 4.75 & 1.32 & 2.67 & 1.35 & & 5.1 & 2.09 & & 3.48 & & 2.2 & & 1.73 & 12.18 \\
\hline Dairy dessert & & 0.9 & & & & 3.17 & & & & & 3.69 & & & & & & 1.15 \\
\hline $\begin{array}{l}\text { Iced confection } \\
\text { Fruit juice/drink }\end{array}$ & & & & & & & & & & & & & & 2.17 & & 1.78 & 1.54 \\
\hline $\begin{array}{l}\text { Fruit juice/drink } \\
\text { Breakfast cereal, } \\
\text { oats/high-sugar }\end{array}$ & & & & & & & & & & & & 4.12 & & & 2.67 & 1.43 & \\
\hline $\begin{array}{l}\text { Flavoured milk/milk } \\
\text { flavouring }\end{array}$ & & 2.49 & & & & & 3.07 & & & & & & & & & 2.11 & \\
\hline $\begin{array}{l}\text { Breakfast cereal, } \\
\text { mixed/high-sugar }\end{array}$ & 0.86 & 1.17 & & & & & 1.03 & & & & & & & & & & \\
\hline Sports drink & & & & & & & & & & & & & & & 3.62 & & \\
\hline Toasted muesli & & & & & & & & & & & & & & & & & 1.67 \\
\hline Liqueur & & & & & & & & & & & & & & & & & 1.43 \\
\hline
\end{tabular}

If public health authorities are to make informed judgements about the health impact of consuming refined sucrose, better access to information on the amounts of sucrose added to processed food is essential.

Discretionary sugar featured as a major contributor to dietary RS for each age group (see Table 2). However, discretionary sugar represented only a small proportion of the RS derived from the 10 most significant sources, compared with sugar added during manufacture or preparation. For example, in 18-year-old boys, discretionary sugar represented only $9.6 \%$ of RS consumption. This supports the notion that manufactured food is the major source of dietary RS in Australia.
One important feature of the major contributors of RS in Table 2 is the prominence of cola-type beverages. The NNS data ${ }^{11}$ indicate that such foods are consumed widely from a young age. Consideration of the dietary role of RS requires a contextual analysis, rather than simply focusing on the metabolic effects of sugar in isolation. Although the association between RS intake and caffeine intake was not tested in the present study, the identification of cola drinks as a major source of RS raises the possibility of sugar as a vehicle for caffeine intake, especially as caffeine becomes more widespread in the Australian food system.

The results of this study indicate that RS consumption by Australian children is generally far in excess of 
recent WHO recommendations ${ }^{1}$. The prominence of highsugar foods in the diets of children warrants further attention, especially considering that the results of this study relate to average figures in the Australian population and they are almost certainly an underestimate of RS intake.

\section{Acknowledgements}

Support for part of this work was provided by a research grant from the Sanitarium Healthfood Company to Griffith University.

\section{References}

1 World Health Organization (WHO). Diet, Nutrition and the Prevention of Chronic Diseases. WHO Technical Report Series No. 916. Geneva: WHO, 2003.

2 Magarey A, Daniels L, Boulton T. Prevalence of overweight and obesity in Australian children and adolescents: reassessment of 1985 and 1995 data against new standard international definitions. Medical Journal of Australia 2001; 174(11): 561-4.

3 Ludwig DS, Peterson KE, Gortmaker SL. Relation between consumption of sugar-sweetened drinks and childhood obesity: a prospective, observational analysis. Lancet 2001; 357(9255): 505-8.

4 National Health and Medical Research Council. Dietary Guidelines for Children and Adolescents. Canberra: Australian Government Publishing Service, 1995.

5 National Health and Medical Research Council. Dietary Guidelines for Australians. Canberra: Australian Government Publishing Service, 1992.

6 Baghurst KI, Record SJ, Syrette JA, Crawford DA, Baghurst $\mathrm{PA}$. Intakes and sources of a range of dietary sugars in various Australian populations. Medical Journal of Australia 1989; 151: 512-8.

7 Australian Bureau of Statistics (ABS). Apparent Consumption of Selected Foodstuffs. Catalogue No. 4315.0. Canberra: ABS, 1998.

8 Nicklas TA, Myers L, Beech B, Berenson GS. Trends in dietary intake of sugars of 10-year-old children from 1973 to 1988: the Bogalusa Heart Study. Nutrition Research 1999; 19(4): 519-30.

9 Gibney M, Sigman-Grant M, Stanton JL Jr, Keast DR. Consumption of sugars. American Journal of Clinical Nutrition 1997; 62(Suppl. 1): 1785-935.
10 Kranz S, Siega-Riz AM. Sociodemographic determinants of added sugar intake in preschoolers 2 to 5 years old. Journal of Pediatrics 2002; 140(6): 667-72.

11 Lien N, Lytle LA, Klepp K-I. Stability in consumption of fruit, vegetables, and sugary foods in a cohort from age 14 to age 21. Preventive Medicine 2001; 33(3): 217-26.

12 McLennan W, Podger A. National Nutrition Survey - Foods Eaten, Australia 1995. Canberra: Australian Bureau of Statistics, 1999.

13 Australian Bureau of Statistics (ABS), National Nutrition Survey 1995 (NNS95). Confidentialised Unit Record File (CURF). Canberra: ABS, 2001.

14 McLennan W, Podger A. National Nutrition Survey User's Guide 1995. Canberra: Australian Government Publishing Service, 1998.

15 National Food Authority. NUTTAB95, Nutrient Data Table for Use in Australia (1995). Canberra: National Food Authority, 1995.

16 Matthews R. Sugar Content of Selected Foods: Individual and Total Sugars. Home Economics Research Report No. 43. Bethesda, MD: US Department of Agriculture, 1987.

17 Wills R. Comparison of sugar levels in sweetened and unsweetened fruit juices and fruit juice drinks. Food Technology Australia 1988; 40: 22-3.

18 Winton AL, Winton K. The Structure and Composition of Foods. Vol. II. New York: John Wiley and Sons, 1947.

19 The Family Circle Recipe Encyclopedia. Sydney: Murdoch Books, 1996.

20 Sweetold-fashioned favourites. The Australian Women's Weekly. Sydney: Australian Consolidated Press, 1995.

21 Freire MdoC, Cannon G, Sheiham A. An analysis of the recommendations on sugar consumption between 1961 and 1991. Revista de Saude Publica 1994; 28: 228-37.

22 Cashel KM, Greenfield H. Principal sources of dietary fat in Australia: evidence from apparent consumption data and the national dietary survey of adults. British Journal of Nutrition 1994; 71(5): 753-73.

23 Mennella J, Beauchamp G. Early flavor experiences: research update. Nutrition Reviews 1998; 56: 205.

24 Mennella JA, Beauchamp GK. Maternal diet alters the sensory qualities of human milk and the nursling's behavior. Pediatrics 1991; 88(4): 737-44.

25 Burley V. Sugar consumption and cancers of the digestive tract. European Journal of Cancer Prevention 1997; 6: 422-34.

26 World Cancer Research Fund (WCRF)/American Institute for Cancer Research (AICR). Food, Nutrition and the Prevention of Cancer: A Global Perspective. Washington, DC: WCRF/AICR, 1997. 